\title{
Efficacy of Early Helicobacter pylori Eradication vs Continuous Pantoprazol Infusion in Prevention of Rebleeding in Peptic Ulcer Patients
}

Abdolrahim Masjedizadeh, Eskandar Hajiani, Seid Jalal Hashemi, Ebrahim Mohamadi, Pezhman Alavi Nejad

\begin{abstract}
Aim: The efficacy of Helicobacter pylori eradication in the prevention of early rebleeding in comparison with proton pump inhibitor (PPI) infusion has not yet been elucidated. This study compares the efficacy of these two therapies in peptic ulcer bleeding patients.
\end{abstract}

Materials and methods: One-hundred and two peptic ulcer bleeding patients with confirmed $H$. pylori infection by rapid urease test and a recent stigmata of hemorrhage were treated with epinephrine injection plus argon plasma coagulation (APC) or bipolar electrocoagulation combination therapeutic endoscopy and consequently, divided into group P (intravenous pantoprazole $80 \mathrm{mg}$ stat and then $8 \mathrm{mg} / \mathrm{h}$ infusion for 72 hours) and group $\mathrm{H}$ (omeprazole $20 \mathrm{mg} \mathrm{BID}$, bismuth subcitrate $240 \mathrm{mg}$ $\mathrm{BID}$, metronidazole $500 \mathrm{mg}$ BID and tetracycline $1,000 \mathrm{mg} \mathrm{BID}$ for 14 days) randomly and blindly.

Results: The average age was 51 (16-89 years) in group $P$ and $50.96(20-74)$ in group $H(p=0.96)$. A total of 64.7 and $52.9 \%$ of patients in each group were male, respectively $(p=0.22)$. The source of bleeding was gastric ulcer in 49 and $45.1 \%$ in groups $P$ and $H$, respectively $(p=0.6)$. The other reason of bleeding was duodenal ulcer in both groups. Distribution of ulcer character (nonbleeding vessel, spurting bleeding, adherent clot and oozing) was similar in both groups $(p=0.83)$. The mean transfusion number was 1.61 and 1.24 in groups $P$ and $H$, respectively $(p=0.11)$. The mean duration of hospitalization was 4.47 and 4.24 days in groups $P$ and $H$, respectively $(p=0.14)$. There was no rebleeding, need to surgery or mortality among the study groups.

Conclusion: Early $H$. pylori eradication as an alternative to intravenous PPI could be effective in preventing early rebleeding of peptic ulcers.

Keywords: Helicobacter pylori eradication, Proton pump inhibitor infusion, Bleeding peptic ulcer.

How to cite this article: Masjedizadeh A, Hajiani E, Hashemi SJ, Mohamadi E, Nejad PA. Efficacy of Early Helicobacter pylori Eradication vs Continuous Pantoprazol Infusion in Prevention of Rebleeding in Peptic Ulcer Patients. Euroasian J HepatoGastroenterol 2013;3(2):124-127.

Source of support: Nil

Conflict of interest: None

\section{INTRODUCTION}

A total of 10 to $35 \%$ of patients with peptic ulcer bleeding experience rebleeding after therapeutic endoscopy. ${ }^{1}$ Intravenous (IV) proton pump inhibitors (PPI) could stabilize the clot and control fibrinolysis by increasing gastric $\mathrm{pH}{ }^{2}$ The role of early $H$. pylori eradication after patient discharge in preventing ulcer recurrence has been confirmed which could decrease the rate of ulcer recurrence to 5 to $20 \%$ in 1 year. $^{3}$ The effect of $H$. pylori eradication in preventing complication and rebleeding during hospitalization has not been investigated so far. H. pylori eradication may accelerate ulcer healing and decrease recurrence and complications such as GI bleeding. ${ }^{4}$ The mechanism of ulcer treatment in decreasing rebleeding has not been completely elucidated, but according to the effects of this infection in increasing gastric acid secretion, producing gastric metaplasia as the immune response and subsiding the defending mechanism of mucosa, early eradication could be useful. ${ }^{5,6}$ In this study, the effect of IV PPI in patients with bleeding peptic ulcer after therapeutic endoscopy has been investigated in comparison with early $H$. pylori eradication.

\section{MATERIALS AND METHODS}

Bleeding peptic ulcer patients older than 16 years who had a stigmata of recent bleeding such as active spurting (Forrest $\mathrm{I}_{\mathrm{A}}$ ), nonbleeding visible vessel (Forrest $\mathrm{II}_{\mathrm{A}}$ ), oozing or adherent clot with visible vessel (Forrest $\mathrm{I}_{\mathrm{B}}$, $\mathrm{II}_{B}, \mathrm{II}_{\mathrm{A}}$ ) were included in the study. The exclusion criteria included esophageal varices, liver cirrhosis, malignancy, concomitant morbidity, cardiac pacemaker, nonsteroidal anti-inflammatory drug (NSAID) consumption, current therapy with anticoagulant, antibiotic or PPI and multiple ulcers.

After achieving endoscopic homeostasis with epinephrine injection $(1: 10,000)$ plus argon plasma coagulation (APC) or bipolar ECT (Table 1), two samples from the antrum and two samples from the corpus were obtained by forceps biopsy. The samples were checked for rapid urease test and all of the positive samples, according to balance block render and by submitting confounding factors such as age, gender and endoscopy results were randomly divided into two groups.

Group P was treated with $80 \mathrm{mg}$ IV bolus injection of pantoprazole and then continuous IV infusion $8 \mathrm{mg} / \mathrm{h}$ for 72 hours. Group H had received H. pylori eradication regimen including omeprazole $20 \mathrm{mg}$ BID, tetracycline $1,000 \mathrm{mg}$ BID, metronidazole $500 \mathrm{mg}$ BID and bismuth subcitrate $240 \mathrm{mg}$ BID for 14 days. The patients risk score was determined according to Rockall score and rebleeding was defined as hematemesis, repeating melena, higher than $2 \mathrm{gr} / \mathrm{dl}$ decrease in hemoglobin level, pulse rate higher than 90 beat/min or a sudden drop in blood pressure. 


\section{RESULTS}

Overall, 102 patients were enrolled in the study between February, 2009 and December, 2011. They were divided into two groups (each group consisting 51 patients) (Table 2). Average age in group $\mathrm{P}$ and $\mathrm{H}$ was 51.1 and 50.96 years, respectively $(p=0.96)$. In group $\mathrm{P}, 62.7 \%$ of the patients were younger than 60 years and $37.3 \%$ were older than 60 years in comparison with 66.7 and $33.3 \%$, respectively in group $\mathrm{H}(\mathrm{p}=0.67)$.
In group P, $64.7 \%$ of the patients were male and $35.3 \%$ female in comparison with 52.9 and 47.1 in group $\mathrm{H}$, respectively $(p=0.22)$ (Table 3$)$. In group $P$, the site of bleeding was the duodenum in $51 \%$ and the stomach in $49 \%$. Bleeding site was in the duodenum in $54.9 \%$ and in the stomach in $45.1 \%$ in group $\mathrm{H}$. According to the hemodynamic status, $43.1 \%$ of group P patients and $39.2 \%$ of group $\mathrm{H}$ patients were stable (Table 4). Orthostatic hypotension was seen in $56.9 \%$ of group $\mathrm{P}$ and $60.8 \%$ of

\begin{tabular}{|c|c|c|c|c|}
\hline & & \multicolumn{2}{|c|}{ Protocol } & \multirow[t]{2}{*}{ Total } \\
\hline & & Bipolar & $A P C$ & \\
\hline \multirow[t]{2}{*}{ Group H } & Count & 15 & 36 & 51 \\
\hline & $\%$ within group & $29.40 \%$ & $70.60 \%$ & $100.00 \%$ \\
\hline \multirow[t]{2}{*}{ Group P } & Count & 21 & 30 & 51 \\
\hline & $\%$ within group & $41.20 \%$ & $58.80 \%$ & $100.00 \%$ \\
\hline \multirow[t]{2}{*}{ Total } & Count & 36 & 66 & 102 \\
\hline & $\%$ within group & $35.30 \%$ & $64.70 \%$ & $100.00 \%$ \\
\hline
\end{tabular}

\begin{tabular}{|c|c|c|c|c|}
\hline & & \multicolumn{2}{|c|}{ Risk score } & \multirow[t]{2}{*}{ Total } \\
\hline & & Intermediate & High & \\
\hline \multirow[t]{2}{*}{ Group H } & Count & 23 & 28 & 51 \\
\hline & $\%$ within group & $45.1 \%$ & $54.9 \%$ & $100.00 \%$ \\
\hline \multirow[t]{2}{*}{ Group P } & Count & 24 & 27 & 51 \\
\hline & $\%$ within group & $47.1 \%$ & $52.9 \%$ & $100.00 \%$ \\
\hline \multirow[t]{2}{*}{ Total } & Count & 47 & 55 & 102 \\
\hline & $\%$ within group & $46.1 \%$ & $53.9 \%$ & $100.00 \%$ \\
\hline
\end{tabular}

\begin{tabular}{|c|c|c|c|}
\hline \multicolumn{4}{|c|}{ Baseline characteristics and results: Characteristic } \\
\hline Age, years: mean (SD) & Group H & Group P & $p$ \\
\hline Gender: $M / F, n / n$ & $51.10(19.39)$ & $50.96(15.90)$ & 0.96 \\
\hline 3 age groups, $<40 / 40-60 />60: n / n / n$ & $18 / 22 / 11$ & $15 / 19 / 17$ & 0.22 \\
\hline Hemodynamic : normal/orthostatic & $32 / 19$ & $34 / 17$ & 0.67 \\
\hline Hypotension: $n / n$ & $22 / 29$ & $20 / 31$ & 0.68 \\
\hline Location of ulcer, stomach/duodenum: $n / n$ & $25 / 26$ & $23 / 28$ & 0.69 \\
\hline Risk score, intermediate/high: $\mathrm{n} / \mathrm{n}$ & $23 / 28$ & $24 / 27$ & 0.84 \\
\hline Endoscopic protocol: bipolar/APC: $n / n$ & $15 / 36$ & $21 / 30$ & 0.21 \\
\hline Packed cell transfusion: mean (SD) & $1.61(1.2)$ & $1.24(1.12)$ & 0.11 \\
\hline Hospital days: mean (SD) & $4.47(0.85)$ & $4.24(76)$ & 0.14 \\
\hline Rebleeding episode: $n$ & 0.00 & 0.00 & ---- \\
\hline Need to surgery: $n$ & 0.00 & 0.00 & ---- \\
\hline Mortality: $\mathrm{n}$ & 0.00 & 0.00 & ---- \\
\hline Drug side effects: $n$ & 0.00 & 0.00 & ---- \\
\hline
\end{tabular}

\begin{tabular}{|c|c|c|c|c|c|c|c|}
\hline & & & \multicolumn{4}{|c|}{ Ulcer } & \multirow[t]{2}{*}{ Total } \\
\hline & & & Clot & Nonbleeding & Oozing & Spurting & \\
\hline \multirow[t]{2}{*}{ Group } & $\mathrm{H}$ & Count & 15 & 16 & 17 & 3 & 51 \\
\hline & & $\%$ within group & $29.40 \%$ & $31.40 \%$ & $33.30 \%$ & $5.90 \%$ & $100.00 \%$ \\
\hline \multirow[t]{2}{*}{ Group } & $P$ & Count & 19 & 14 & 16 & 2 & 51 \\
\hline & & $\%$ within group & $37.30 \%$ & $27.50 \%$ & $31.40 \%$ & $3.90 \%$ & $100.00 \%$ \\
\hline \multirow[t]{2}{*}{ Total } & & Count & 34 & 30 & 33 & 5 & 102 \\
\hline & & $\%$ within group & $33.30 \%$ & $29.40 \%$ & $32.40 \%$ & $4.90 \%$ & $100.00 \%$ \\
\hline
\end{tabular}


group $\mathrm{H}$ patients $(\mathrm{p}=0.68)$. There was no case of shock in any of the groups.

The mean number of transfusions was 1.61 unit in group $\mathrm{P}$ and 1.24 in group $\mathrm{H}(\mathrm{p}=0.11)$. The mean duration of hospitalization in groups $\mathrm{P}$ and $\mathrm{H}$ was 4.47 and 4.24 days, respectively $(\mathrm{p}=0.14)$.

\section{STATISTICS}

According to recurrence rate of $22 \%$ in group $\mathrm{P}^{7}$ and $4 \%$ in group $\mathrm{H}^{8},{ }^{8}$ the sample size of 51 patients in each group was determined to achieve the accuracy rate of $90 \%$. For determining differences between mean values, t-test was used. A p-value of less than 0.05 was considered statistically meaningful. The effect of treatment on rebleeding, need for transfusion and duration of admission was determined by using a multivariate logistic regression ratio. This study has registered in IRCT (Iranian Registry of Clinical Trials) as number IRCT201108073836N2.

\section{DISCUSSION}

The risk of rebleeding in patients with bleeding peptic ulcer is higher than noncomplicated ulcer disease. ${ }^{9}$ Almost one-third of patients with bleeding peptic ulcer during 1 to 2 years and 40 to $50 \%$ of them during 10 years will experience rebleeding if given no treatment. ${ }^{10}$ So the two strategies of 'H. pylori eradication' and 'maintenance antisecretory therapy' would be effective in preventing ulcer recurrence and complication. The previous studies had focused on therapeutic PPI infusion after endoscopic homeostasis in treatment of bleeding peptic ulcers and had reduced the rate of rebleeding [number of need to treat (NNT): 13; 95\% confidence interval (CI): 9-25; odd ratio (OR): 0.49; 95\% CI: $0.37-0.65]^{11,12}$

In patients who have had experienced peptic ulcer bleeding, $H$. pylori eradication has been accompanied with a lower risk of rebleeding in comparison with maintenance antisecretory therapy. In three studies on 470 patients, it has been shown that the risk of rebleeding in $H$. pylori eradication group is $1.6 \%$ and in patients who receive maintenance antisecretory regimen this risk is 5.6\% (OR: 0.25, 95\% CI: 0.08-0.76, NNT: 20, 95\% CI: 12-100).

In another study, acceleration in $H$. pylori eradication resulted in the decreased rate of readmission of patients with peptic ulcer. This study also showed that early H. pylori eradication during first 6 months after peptic ulcer, would be accompanied with a lower risk of hospitalization due to complication of ulcer in comparison with late eradication (181-365 days or $>365$ days) $(\mathrm{HR}=0.57$; CI: 0.54-0.59; $\mathrm{p}<0.001$ for early eradication in less than 6 months in comparison with late therapy from 181 to 365 days, $\mathrm{HR}=$ 1.68; CI: 1.51-1.86; $\mathrm{p}<0.001$; and after 365 days, $\mathrm{HR}=$ 1.74; CI: $1.67-1.80 ; \mathrm{p}<0.001){ }^{13,14}$

No study has investigated the effect of continuous IV PPI infusion on the rate of rebleeding, need to surgery and mortality in comparison with immediate early $H$. pylori eradication in patients with bleeding peptic ulcer after endoscopic homeostasis. In this study, patients with bleeding peptic ulcer who were treated with endoscopic homeostasis by combination of adrenalin injection and APC or bipolar were randomly divided into two groups: $H$. pylori eradication and IV PPI infusion. The results of this study have not showed any difference in the rate of rebleeding, duration of admission, blood transfusion, need to surgery or mortality as primary and secondary outcome in the first week and first month between the two groups. The mean rebleeding rate with PPI infusion was $6.7 \%$. This rate has been reported $13 \%$ with continuous pantoprazole infusion ${ }^{15}$ and in our study; this figure was significantly lower than the previous studies. The reason of this difference could be explain by lesser number of patients in our study, the lower number of patients with spurting bleeding, use of combination endoscopic homeostatic therapy, exclusion of patients who consumed NSAID and also genetic or geographic reasons.

\section{CONCLUSION}

This study confirms the importance of early $H$. pylori eradication in patients with bleeding peptic ulcer who have stigmata of hemorrhage and have received therapeutic endoscopy. Our findings showed that in this group of patients, early $H$. pylori eradication could be as effective as IV PPI infusion in preventing rebleeding, need to surgery and mortality and also due to the lower cost could be a good therapeutic alternative.

\section{ACKNOWLEDGMENTS}

This work was supported without grants by Digestive Disease Research Centre, Ahvaz Jundishapur University of Medical Sciences, Ahvaz, Iran. We are grateful to Research deputy of Ahvaz Jundishapur University of Medical Sciences for his encouragement and constructive advice during the preparation of the manuscript.

\section{REFERENCES}

1. Lau JY, Sung J, Hill C, Henderson C, Howden CW, Metz DC. Systematic review of the epidemiology of complicated peptic ulcer disease: incidence, recurrence, risk factors and mortality. Digestion 2011;84:102-113.

2. Lin HJ. Role of proton pump inhibitors in the management of peptic ulcer bleeding. World J Gastrointest Pharmacol Ther 2010 Apr;1(2):51-53. 
3. Kim JJ, Kim N, Lee BH, Kang JM, Seo P, Lim MK, Kwon JH, Song BJ, Lee JW, Lee SH, et al. Risk factors for development and recurrence of peptic ulcer disease. Korean J Gastroenterol 2010 Oct;56(4):220-228.

4. Ryu KH, Yi SY, Na YJ, Baik SJ, Yoon SJ, Jung HS, Song HJ. Reinfection rate and endoscopic changes after successful eradication of Helicobacter pylori. World J Gastroenterol 2010 Jan;16(2):251-255.

5. Kato M, Ono S, Yoshida T, Mabe K, Shimizu Y, Asaka M. Significance of $\mathrm{H}$. pylori eradication in treatment and prevention for low-dose aspirin induced gastric ulcer of elderly. Nippon Rinsho 2010 Nov;68(11):2089-2095.

6. Venerito M, Malfertheiner P. Interaction of Helicobacter pylori infection and nonsteroidal anti-inflammatory drugs in gastric and duodenal ulcers. Helicobacter 2010 Aug;15(4):239-250.

7. Garrido A, Iborra MI, Saperas E, de Sousa M. En representación del Grupo PREVENT. Prevalence of rebleeding from peptic ulcer in patients treated with proton pump inhibitors. Med Clin (Barc) 2010 Feb;134(13):577-582.

8. Li Z, Zou D, Ma X, Chen J, Shi X, Gong Y, Man X, Gao L, Zhao Y, Wang R, et al. Epidemiology of peptic ulcer disease: endoscopic results of the systematic investigation of gastrointestinal disease in China. Am J Gastroenterol 2010 Dec;105(12):2570-2577.

9. Chiu PW. Bleeding peptic ulcers: the current management. Dig Endosc 2010 Jun;22(Suppl)1:S19-S21.

10. Cheng CL, Lin CH, Kuo CJ, Sung KF, Lee CS, Liu NJ, Tang JH, Cheng HT, Chu YY, Tsou YK. Predictors of rebleeding and mortality in patients with high-risk bleeding peptic ulcers. Dig Dis Sci 2010 Sep;55(9):2577-2583.

11. Leontiadis GI, Sharma VK, Howden CW. Systematic review and meta-analysis: proton-pump inhibitor treatment for ulcer bleeding reduces transfusion requirements and hospital stay-results from the Cochrane Collaboration. Aliment Pharmacol Ther 2005 Aug;22(3):169-174.

12. Van Rensburg C, Barkun AN, Racz I, Fedorak R, Bornman PC, Beglinger C, Balanzó J, Devière J, Kupcinskas L, Luehmann $\mathrm{R}$, et al. Clinical trial: intravenous pantoprazole vs ranitidine for the prevention of peptic ulcer rebleeding: a multicentre, multinational, randomized trial. Aliment Pharmacol Ther 2009 Mar;29(5):497-507.
13. Zargar SA, Javid G, Khan BA, Yattoo GN, Shah AH, Gulzar GM, Sodhi JS, Mujeeb SA, Khan MA, Shah NA, et al. Pantoprazole infusion as adjuvant therapy to endoscopic treatment in patients with peptic ulcer bleeding: prospective randomized controlled trial. J Gastroenterol Hepatol 2006 Apr;21(4):716-721.

14. Barkun AN, Herba K, Adam V, Kennedy W, Fallone CA, Bardou M. High-dose intravenous proton pump inhibition following endoscopic therapy in the acute management of patients with bleeding peptic ulcers in the USA and Canada: a cost-effectiveness analysis. Aliment Pharmacol Ther 2004 Mar;19(5):591-600.

15. Lanas A, Aabakken L, Fonseca J, Mungan ZA, Papatheodoridis GV, Piessevaux H, Cipolletta L, Nuevo J, Tafalla M. Clinical predictors of poor outcomes among patients with nonvariceal upper gastrointestinal bleeding in Europe. Aliment Pharmacol Ther 2011 Jun;33(11):1225-1233.

\section{ABOUT THE AUTHORS}

\section{Abdolrahim Masjedizadeh (Corresponding Author)}

Gastroenterologist, Department of Gastroenterology, Ahwaz Jondishapur Medical University, Khouzestan, Iran, e-mail: masjed-ri@ajums.ac.ir

\section{Eskandar Hajiani}

Gastroenterologist, Department of Gastroenterology, Ahwaz Jondishapur Medical University, Khouzestan, Iran

\section{Seid Jalal Hashemi}

Gastroenterologist, Department of Gastroenterology, Ahwaz Jondishapur Medical University, Khouzestan, Iran

\section{Ebrahim Mohamadi}

Internist, Department of Internal Medicine, Ahwaz Jondishapur Medical University, Khouzestan, Iran

\section{Pezhman Alavi Nejad}

Gastroenterologist, Department of Gastroenterology, Ahwaz Jondishapur Medical University, Khouzestan, Iran 